\title{
Paramolar tubercle in the left maxillary second premolar: a case report.
}

\author{
Carolina Rodríguez ${ }^{1}$ and Freddy Moreno ${ }^{2 *}$
}

${ }^{1}$ Department of Orthodontics and ${ }^{2}$ Oral and Maxillofacial Surgery Research Group (Dental Anthropology and Forensic Dentistry), School of Dentistry, University of Valle, Cali, Colombia.

ABSTRACT: This is a case report describing a paramolar tubercle occurring on the buccal surface of left upper second premolar (tooth 25). From the perspective of dental anthropology, this morphological feature, though uncommon, may be useful for classification and identification. Dental Anthropology 2006;19(3):65-69.
Dental anthropology can be viewed as the collaborative effort of anthropology, clinical dentistry, biology, paleontology, and paleopathology. The resulting knowledge base permits the study, analysis, interpretation, and understanding of information derived from the human dentition through their morphological, evolutionary, pathological, cultural and therapeutic variations. These structural considerations are viewed against a people's culture, notably the conditions of life, diet, and adaptation processes. The varied sorts of data studied include nonmetric traits, metric traits, oral and dental diseases, and structural modifications of the teeth. Dental morphology, particularly the study of nonmetric dental traits (NDT), involves genetically-modulated trait expressions that can be used for comparisons within and among populations (Scott and Turner, 1997, 1998; Rodríguez CD, 2003, 2005; Rodríguez and Delgado 2000; Rodríguez JV, 2003).

More than 100 NDT of dental crowns and roots have been described and standardized internationally using various methodologies. Their study and investigation have demonstrated that: (a) they possess high taxonomic value; (b) they can be used to estimate biological relationships among diverse populations, which allows comparative analyses of the historical, cultural and biological development of primitive and modern human groups; (c) most NDT have low sexual dimorphism, low correlations among features, and low correspondence between frequency and geography; $(\mathrm{d})$ they are easily observed and recorded; and (e) they can be used to evaluate population differences according to micro-evolutionary processes, that, in turn, generate information about human movements and contacts that have produced groups' ethnic variation (Scott and Turner, 1997; Zoubov, 1997; Rodríguez JV, 2003).

Within the broad study of dental morphology, one feature that stands out is the tubers paramolares. These NDTs are not common, and, especially in the clinical dental literature, they are viewed as supernumerary cusps or ill-defined anatomical variations. Basically, paramolar tubercles occur as accessory cusps located on the buccal or lingual surface of the primary and succedaneous teeth, involving both the maxillary or mandibular tooth types. Several of these morphological variants are broadly recognized in the dental anthropological literature, such as the dental tubercle on the lingual surface of the upper lateral incisors; the UtoAztecan or distosagittal crest on the buccal surface of the upper first premolar; Carabelli's trait on the lingual surface of the mesolingual cusp of the upper molars; the parastyle on the buccal surface of the upper molars; the protostylid on the buccal surface of the low first molars; and paramolar tubercles, generally developed on the buccal surfaces of the upper and low premolars and molars (Zoubov, 1997; Turner and Harris, 2004).

\section{PARAMOLAR TUBERCLES}

One NDT that has been described as an accessory or supernumerary cusp, was defined by A. A. Dahlberg in 1950 as a paramolar tubercle, a term applied nonspecifically to a style or cusp of supernumerary character that is developed on the buccal or lingual surfaces of the upper and low premolars and molars (Turner and Harris, 2004).

Developmentally, dental cusps begin their formation during the early bell stage, well before calcification of the tooth has begun. The cells of the internal epithelium proliferate and produce activators and inhibitors while they are being deposited in sequential layers from the

*Correspondence to: Freddy Moreno, Universidad del Valle - Sede San Fernando, Escuela de Odontología, Calle 4B No. 36-00 Edificio 132 Oficina 308. A.A. 25360, Cali - Colombia

E-mail: freddyodont@hotmail.com 


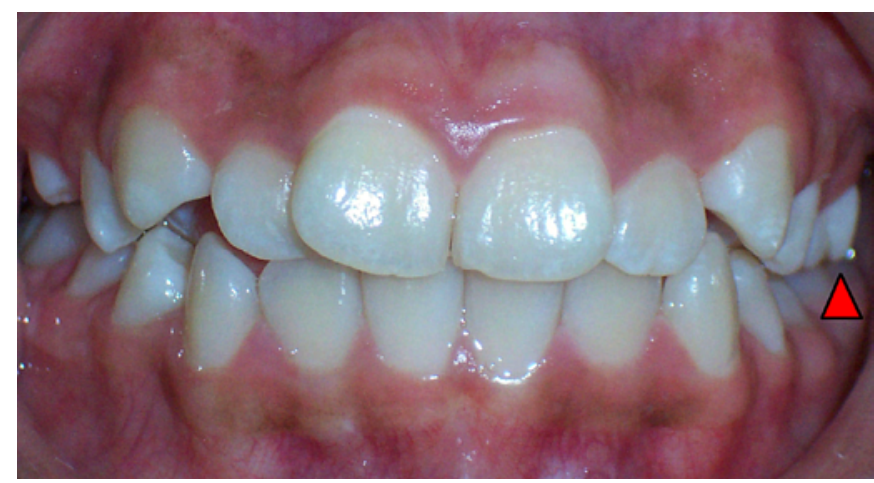

Fig. 1. Clinical front view: paramolar tubercle on the left maxillary second premolar (arrow).

cusp apex toward the neck of the crown starting from an enamel knot. The activator produces a primary enamel knot until the concentration reaches a threshold that induces an inhibitor that neutralizes the activator. Once a primary enamel knot has developed, it subsequently disappears by means of apoptosis and secondary enamel knots may appear. Molecular biologists are beginning to understand the genes that code and control the expression of the activator and the inhibitor that modulate the rhythm and quantity of enamel deposition. These transient gene expressions modulate the formation and elevation of the peaks and crests leaving among them furrows and grooves.

Consequently, the formation of a NDT (a cusp, for example) begins with primary or secondary enamel knot. The form of the NDT is influenced by the amount (thickness) of enamel deposited, size of the crown, its relationship with other NDT, and its internal relationship with the dentine. The NDT's configuration depends, on one hand, on the molecular patterns that are genetically determined and, on the other hand, on the trait's relationship with other morphological features

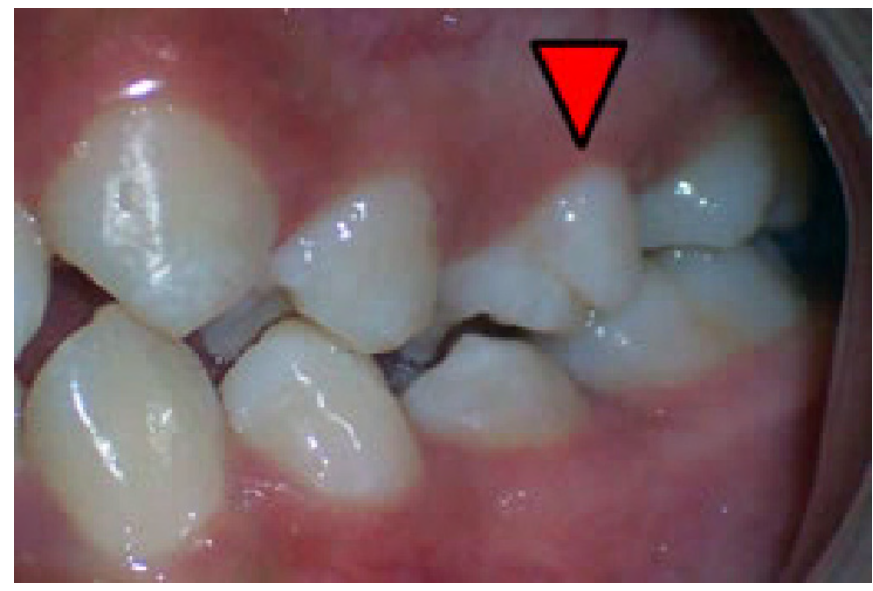

Fig. 3. Clinical right view: paramolar tubercle on the left maxillary second premolar (arrow).

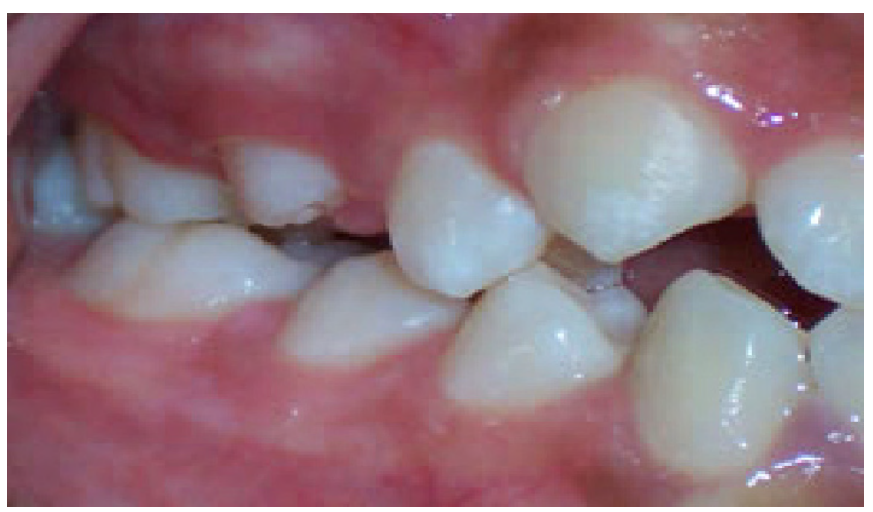

Fig. 2. Clinical right view. where the premolars lack any evidence of a tubercle.

(Butler, 1995; Jernvall et al., 1994; Jernvall and Jung, 2000; Jernvall and Thesleff, 2000; Line, 2001; Thesleff and Sharpe, 1997).

Dental studies in the field of the molecular biology derive in part from the work of Thesleff et al. (e.g., 2001). Research demonstrates that the primary enamel knot configures the occlusal table of premolars and molars, while secondary enamel knots individually constitute the cusps during amelogenesis (Thesleff, 2003; Turner and Harris, 2004).

In the case of the paramolar tubercle, Turner and Harris (2004) suggest that such cusps arise during the morphogenesis process starting from an accessory enamel knot developed at the surface where the feature's apex forms. It seems that these tubercles do not provide any functional adaptation, such as enlarging the occlusal (masticatory) surface, because these tubercles do not enter into function; they do not occlude against any cusp or groove of the antagonist tooth.

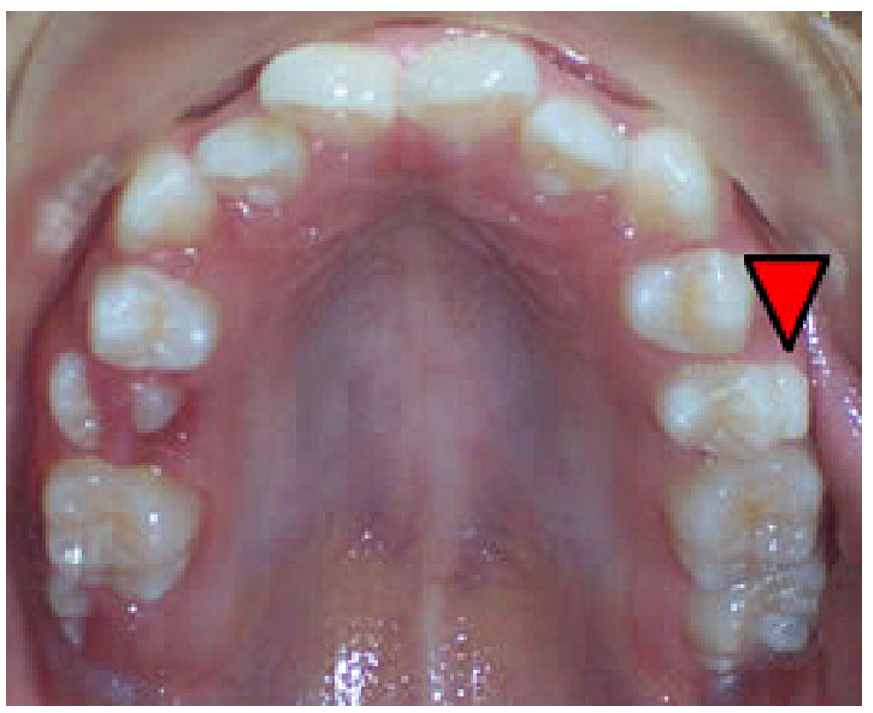

Fig. 4. Clinical oclusal view: paramolar tubercle on the left maxillary second premolar (arrow). 


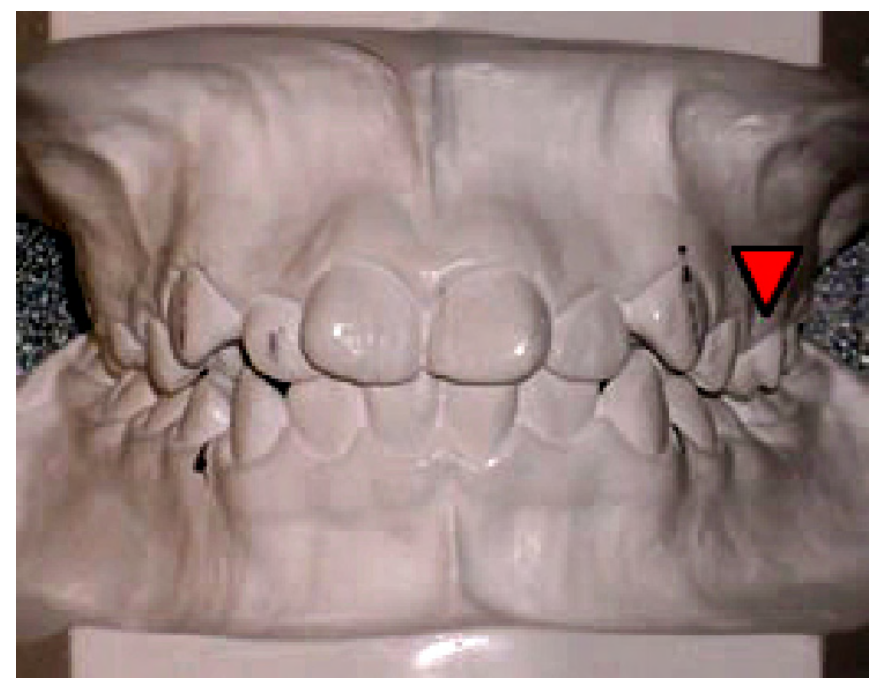

Fig. 5. Clinical frontal view of the articulated study models: paramolar tubercle on the left maxillary second premolar (arrow).

To date, there is very little information about racial differences in the frequencies of paramolar tubercles, primarily because of their apparently low occurrence overall. Likewise, no pedigree analysis seems to have been conducted, though their mode of inheritance seems to be complex. Alternatively, their expression may suggest a genetic relationship between individuals. For instance, if the tubercle were found in two coeval individuals in a population, this increases the likelihood that the persons are genetically related, which can be useful for forensic identification (Zoubov, 1997; Edgar, 2005).

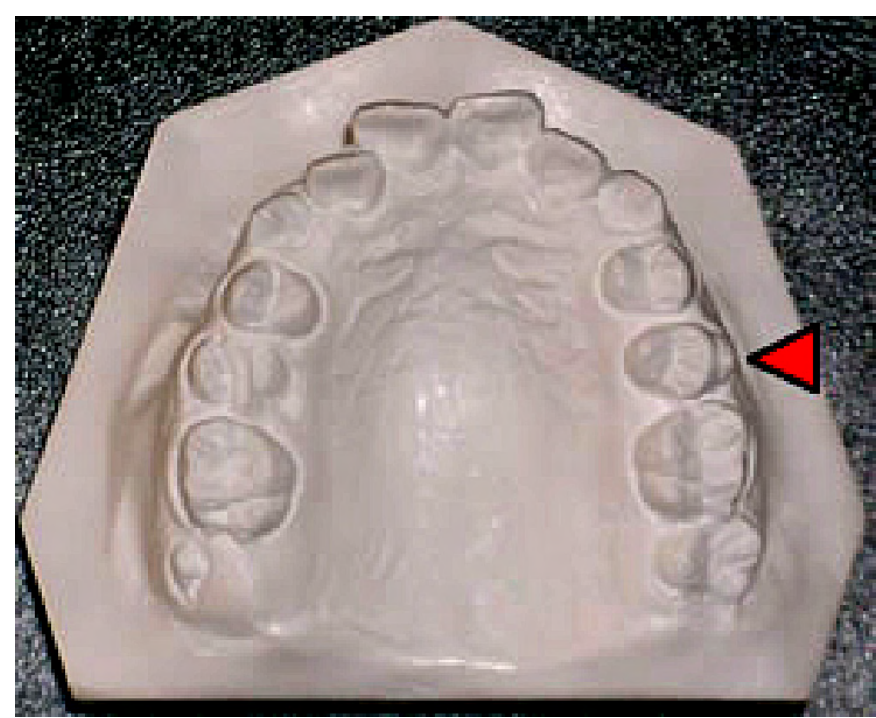

Fig. 7. Oclusal view of the maxillary study model: paramolar tubercle on the left maxillary second premolar (arrow).

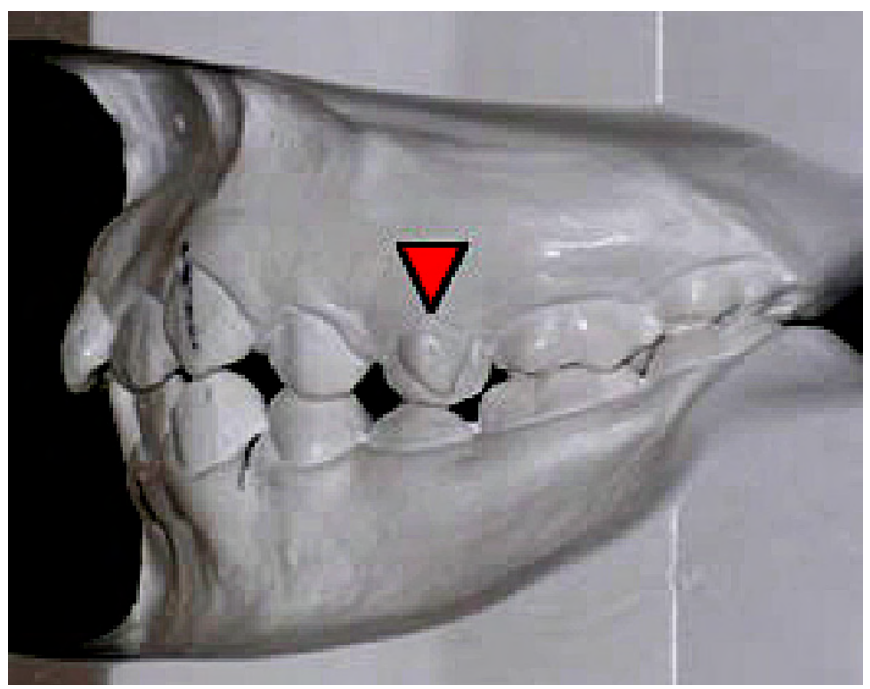

Fig. 6. Left view of the articulated study models: paramolar tubercle on the left maxillary second premolar (arrow).

\section{CASE REPORT}

The subject is an eleven-year-old girl attending the orthodontic clinic at the School of Dentistry of the University of the Valley, Colombia.

Assessment of the maxillofacial skeleton disclosed a slight Class II sagittal molar relationship; upper and low arches were of an oval form; there was slight mandibular retrognathism; the facial form was mesofacial and there was a vertical growth pattern. Diagnosis of the soft tissue showed a convex facial profile, a moderate mentolabial furrow, a normal nasolabial angle, protrusion of both the upper and lower lips, and an increased height of the inferior third of the face. The stomatoghnatic functional diagnosis disclosed bruxism and a preference for unilateral right mastication. The dental diagnosis

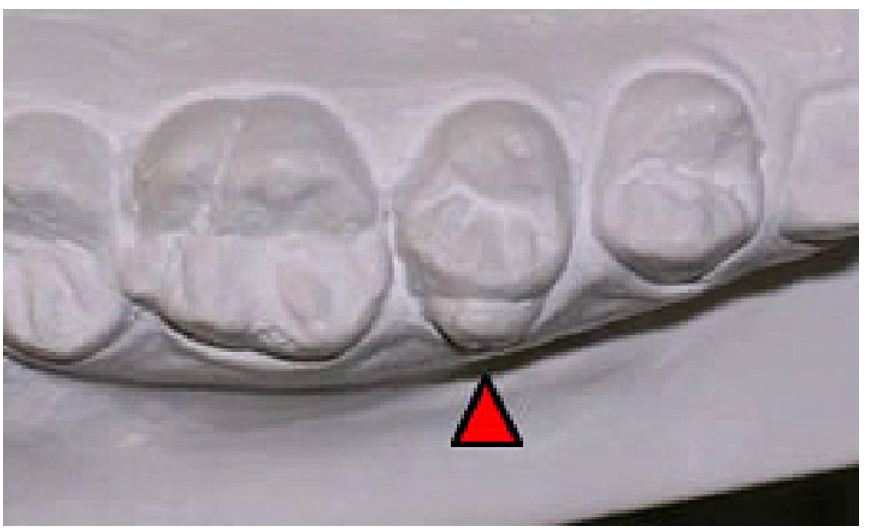

Fig. 8. Oclusal view of the maxillary study model: paramolar tubercle on the left maxillary second premolar (arrow). 


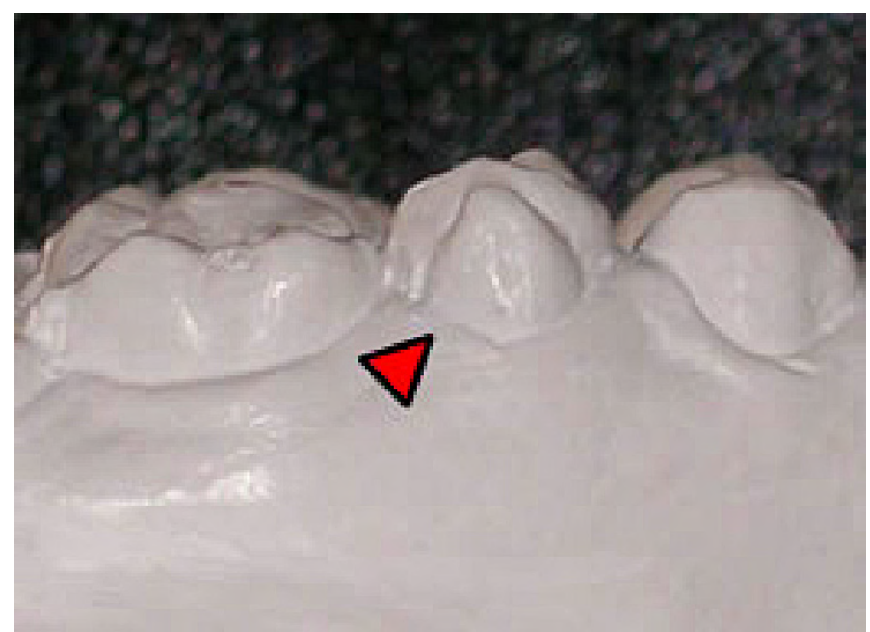

Fig. 9. Buccal view of the maxillary study model: paramolar tubercle on the left maxillary second premolar (arrow).

showed that the girl presents a complete permanent dentition (omitting the third molars), a Class I molar malocclusion, a Class II canine relationship, proclination of the mandibular incisors, moderate crowding in both arches, deviation of the dental midlines, and traumatic occlusion.

This NDT of interest here is a unilateral paramolar tubercle that on the buccal surface of the upper left second premolar. Viewed in the frontal plane (Figs. 1, 5), the tubercle presents a free cusp apex that does not reach the occlusal plane. Indeed, the tubercle is out of function since there is no occluding anatomical structure on the opposing mandibular teeth. In buccal view (Figs. $3,6,9)$, the tubercle constitutes a triangular prominence with its base below the gingival margin and its apex oriented occlusally. This cusp is aligned with that of the premolar's buccal cusp. From the occlusal view (Figs. $4,7,8)$, one can appreciate the symmetrical prominence of the tubercle, which is centered mesiodistally along the tooth's buccal surface. The longitudinal furrow is evident here, and it runs mesial to distal, separating the tubercle from the premolar's primary cusp.

Other NDTs that can be appreciated in the patient are: (A) Crowding of the upper incisors (Figs. 4, 7), where the lateral incisors are lingually displaced and there is a consequent tooth-size to arch-size discrepancy (Rodríguez, 1989; Bernabé and Flores, 2006). (B) Slight incisor winging (Figs. 4, 7), where both upper central incisors are slightly rotated distolingually relative to the midline; in this case, winging probably is secondary to inadequate arch space for correct incisor alignment (Peck and Peck, 1975; Rodríguez JV, 1989, 2003; Turner et al., 1991; Nandini et al., 2005; Bernabé and Flores, 2006). (C) Cusp 7 (grade 5) occurs bilaterally, which is an NDT characteristic of Negroid populations (Zoubov, 1997). (D) Cusp 6 (grade 2) occurs bilaterally. (E) A deflecting

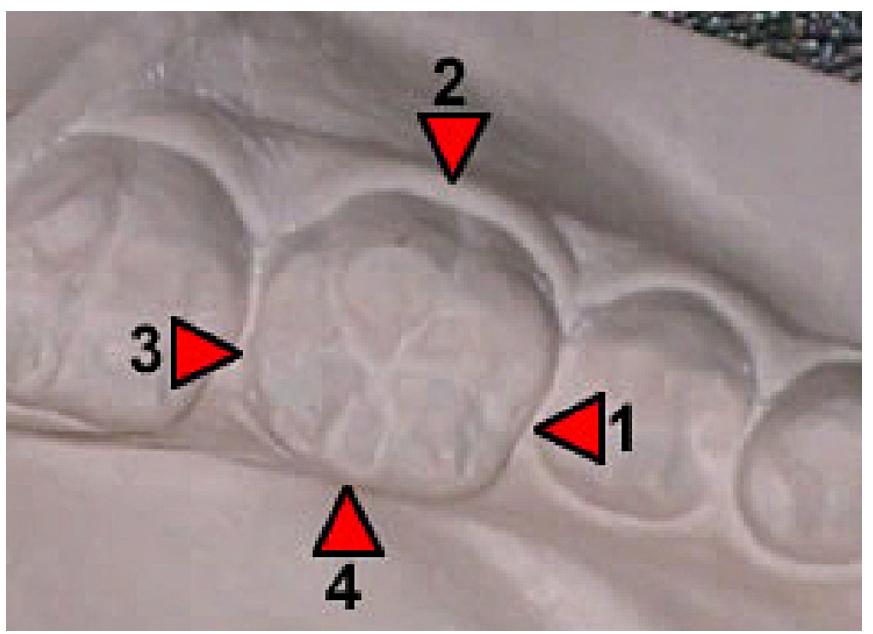

Fig. 10. Numerical codes are: (1) deflecting wrinkle; (2) protostylid; (3) cusp 6; and (4) cusp 7.

wrinkle (grade 3) can be seen on the first molars. (F) The molar cusp arrangement yields a $\mathrm{Y} 6$ groove pattern (mesiolingual cusp contacts with the distobuccal cusp at the central groove). (G) A protostylid pit occurs bilaterally (Fig. 10), which is a common NDT in mixed population from Colombia (Moreno et al., 2004; Moreno and Moreno, 2005; Aguirre et al., 2006).

\section{RECOMMENDATIONS}

It is important to recognize that although some NDTs, including the paramolar tubercles, only occur in low frequencies, they should not be classified as anomalous (a perspective common in clinical dentistry) since they are normal morphological features of the dentition. This morphological variation is evidenced by the diverse trait frequencies among world populations. Of course, this variability often is capitalized on in the processes of an individual's forensic identification.

It should be noted that, during orthodontic treatment, paramolar tubercles often are removed by ameloplasty (i.e., the selective removal of enamel by grinding) because they interfere with cementation of the brackets and correct alignment of orthodontic archwires. However, this clinical procedure should be considered a last option, since it involves the mutilation of an epigenetic variant of the dental morphology.

It is important that NDTs are described systematically (by form and position) in each person's clinical dental history because these variants are of discriminatory value and because of their usefulness in the identification processes carried out during the technical and scientific exercise of forensic dentistry.

\section{LITERATURE CITED}

Aguirre L, Castillo D, Solarte D, Moreno F. 2006. Frequency and variability of five non-metric dental 
crown traits in the primary and permanent dentitions of a racially mixed population from Cali, Colombia. Dental Anthropology 19:39-47.

Bernabé E, Flores-Mir C. 2006. Dental morphology and crowding: a multivariate approach. Angle Orthod 76:20-25.

Butler PM. 1995. Ontogenetic aspects of dental evolution. Int J Dev Biol 39:25-34.

Edgar HJ. 2005. Prediction of race using characteristics of dental morphology. J Forensic Sci 50:1-5.

Jernvall J, Kettunen P, Karavanova I, Martin LB, Thesleff I. 1994. Evidence for the role of the enamel knot as a control center in mammalian tooth cusp formation. Int J Dev Biol 38:463-469.

Jernvall J, Jung HS. 2000. Genotype, phenotype and develpomental of biology of molar tooth characters. Yrbk Phys Anthropol 43:171-190.

Jernvall J, Thesleff I. 2000. Reiterative signaling and patterning during mammalian tooth morphogenesis. Mech Develop 92:19-129.

Line S. 2001. Molecular morphogenetic fields in the development of human dentition. J Theor Biol 211:67-75.

Moreno F, Moreno SM, Díaz CA, Bustos EA, Rodríguez JV. 2004. Prevalence and variability of eight nonmetric dental traits in students of Cali, Colombia. Colomb Med 35(Supl 1):17-23. (In Spanish)

Moreno SM, Moreno F. 2005. Eight non-metric dental traits in alive racially mixed population from Cali, Colombia. Int J Dental Anthropol 6:14-25.

Nandini V, Utreja A, Goyal A, Chawla HS. 2005. Winged maxillary central incisors with unusual morphology: a unique presentation and early treatment. Angle Orthod 75:427-431.

Peck S, Peck H. 1975. Orthodontic aspects of dental anthropology. Angle Orthod 45:95-102.

Rodríguez CD. 2003a. Prehispanic dental anthropology: biological variation and distances in the population buried in the pre-hispanic cemetery of Obando, Valle del Cauca, Colombia between the centuries VIII and XIII A.D. Miami: Syllaba Press. (In Spanish)
Rodríguez CD. 2005. Dental anthropology and your importante in the human groups study. Rev Fac Odont Univ Ant 16:52-59. (In Spanish)

Rodríguez CD, Delgado ME. 2000. Dental anthropology: a brief definition. Int J Dental Anthropol 1:2-4.

Rodríguez JV. 1989. Introducción a la antropología dental. Cuadernillo de antropología No. 19. Universidad Nacional de Colombia, Facultad de Ciencias Humanas, Departamento de Antropología. Santa fe de Bogotá.

Rodríguez JV. 2003. Teeth and human diversity: dental anthropology advances. Bogotá: Universidad Nacional of Colombia. (In Spanish)

Scott GC, Turner II CG. 1997. The anthropology of modern human teeth: dental morphology and its variation in recent human populations. London: Cambridge University Press.

Scott GC, Turner II CG. 1998. Dental anthropology. Ann Rev Anthropol 17:99-126.

Thesleff I. 2003. Developmental biology and building a tooth. Quintessence Int 34:613-620.

Thesleff I, Sharpe P.1997. Signalling networks regulating dental. Mech Develop 67:111-123.

Thesleff I, Keranen S, Jernvall J. 2001. Enamel knots as signaling centers linking tooth morphogenesis and odontoblast differentiation. Adv Dent Res 15:14-18.

Turner CG II, Nichol CR, Scott GR. 1991. Scoring procedures for key morphological traits of the permanent dentition: the Arizona State University dental anthropology system. In: Kelly MA, Larsen CS, editors. Advances in dental anthropology. New York: Wiley-Liss Inc, p 13-31.

Turner RA, Harris EF. 2004. Maxillary second premolars with paramolar tubercles. Dental Anthropology 17:75-78.

Zoubov AA. 1998. The dental anthropology and de forensic practice. Maguaré 13:243-252. (In Spanish) 